Nevşehir Bilim ve Teknoloji Dergisi Cilt 6(ICAFOF 2017 Özel Sayı) 192-197 2017

DOI: 10.17100/nevbiltek.331894

URL: http://dx.doi.org/10.17100/nevbiltek.331894

\title{
Termal Yöntemlerle Tarımda ve Şehir Yaşam Alanlarında Yabancı Ot Kontrolünün Teknik Yönden Değerlendirilmesi
}

\author{
Ali Bayat ${ }^{1}$, Ali BOLAT ${ }^{2, *}$, Medet ITTMEÇ ${ }^{1}$ \\ ${ }^{1}$ Çukurova Üniversitesi Zir. Fak. Tarım Makinaları ve Teknolojileri Mühendisliği Bölümü, Adana/Turkey \\ ${ }^{2}$ Doğu Akdeniz Tarımsal Araştırma Enstitüsü Müdürlüğü, Adana/Turkey \\ Öz
}

Türkiye de yılda ortalama 40-45 bin ton tarım ilacı kullanılmaktadır. Bu ilaçların önemli bir miktarı yabancı otlarla mücadelede kullanılmaktadır. Ancak son yıllarda kimyasal mücadele maliyetlerinin artışı, herbisitlerin insan ve çevreye olan olumsuz etkilerinin kavranması, organik ve tıbbi bitki tarımının önem kazanması ve ayrıca her yıl herbisitlere dayanıklılık kazanan yabancı ot tür sayısının artması, dünya bilim adamlarını herbisite alternatif olabilecek yöntemlerin araştırılmasına itmiştir. Yabancı otlarla mücadelede herbisitler dışında en ümit var yöntemler, termal yöntemler olarak görünmektedir. Çünkü bu yöntemler, kontrollü uygulandığında çevreye yaydıkları emisyonlar çevre açısından bir risk taşımamaktadır. En yaygın olarak araştırmalara konu olan termal yöntemler; alevle, sıcak su, buhar ve yeni bir teknik olan infrared ışınımla yabancı otların kontrolünden oluşmaktadır. Ancak bu yöntemlerin en önemli sorunlarından bazıları, sistemlerin işletilmesindeki yüksek yakıt maliyetleri, farklı ot çeşitlerine göre değişen etkinlik, alevle mücadeledeki yangın riski ve yüksek ısı nedeniyle kültür bitkisi dokularına verilen zarardan oluşmaktadır. $\mathrm{Bu}$ çalışmada, kimyasal olmayan bazı yabancı ot kontrol yöntemlerine yer verilmiştir.

Anahtar Kelimeler: Termal yöntemler, alevle ot kontrolü, sıcak su uygulama, buharla ot kontrolü, infrared ışınımla ot kontolü

\section{Technical Evaluation of Thermal Weed Control Methods in Agriculture and Urban Areas}

\begin{abstract}
Pesticide consumption is about 40 to 45 tons per year in Turkey and a valuable amount of this consumption is consisted of herbicides which are used in weed control. But, due to increasing of pesticide cost, concerns about pesticides' risks on environment and human life, increasing interest to organic farming and medical plants, increasing the resistance of some weed sorts to herbicides, scientists have trended to find new alternatives to the herbicides. Besides of herbicides, the most preferable methods seem to be thermal methods. Because, the emissions of these methods don't include any environmental risks if these methods were operated in an appropriate situation. The common thermal methods which are subjected to researches are flaming, hot water, steam and infrared heater that is known a new technology in weed control. However, the some concerns and problems regarding with these thermal methods consist of high fuel expenses, variable effects depending on the weed sorts, fire risks in flaming and potential head risk on cultivated plants’ tissue injuries. In this paper, some thermal weed control methods were given and discussed.
\end{abstract}

Keywords: Thermal methods, flaming the weed, hot water application, steaming the weed, infrared radiation for weed control

* e-mail: bolat.ali@tarim.gov.tr 


\section{Nevşehir Bilim ve Teknoloji Dergisi Cilt 6(ICAFOF 2017 Özel Sayı) 192-197 2017}

\section{Giriş}

Tarım alanlarında yabancı otlar, kültür bitkisiyle su, ışık ve yer için rekabete girerek ürün azalmasına neden olmaktadırlar. Yabancı otlardan dolayı dünya üzerindeki tarımsal üretimde ortalama olarak \% 10 oranında bir kayıptan bahsedilirken, ülkemizde yabancı otlardan dolayı ürün kayıpları \% 50' lerin üzerine çıkabilmektedir [1]. Yabancı otlarla mücadelede, işgücünün ucuz olduğu yıllarda yaygın olarak mekanik yöntemlerle yabancı ot mücadelesi yapılırken, günümüzde artan işgücü maliyetleri ve gerektiğinde iş gücü teminindeki sıkıntılar nedeniyle üreticilerin sıklıkla kimyasal mücadele yöntemlerine başvurdukları görülmektedir. Kimyasal mücadele uygulanabilirliğinin kolay olması ve kısa sürede etki göstermesi nedeniyle, günümüzde en çok tercih edilen yöntemdir. Ülkemizde yılda ortalama 40-45 bin ton tarım ilacı kullanılmakta, zararlılara karşı kullanılan ilaçlar dışında en yüksek tarım ilacı kullanımı, yabancı otlarla mücadelede kullanılmaktadır. Ancak kimyasal ilaçların gerek insan ve gerekse çevre sağlığı üzerindeki bilinen olumsuzluklarının yanı sıra, giderek artan ilaçsız ürün talebi, tarım alanlarında hastalık, zararlı ve yabancı otlarla mücadelede çevre dostu yeni teknolojilerin ve taktiklerin kullanılmasını gerektirmektedir. Özellikle organik tarım alanlarında, yabancı otlarla mücadelede kullanılabilecek ruhsatlı hiçbir ilaç/kimyasal bulunmaktadır. Ancak, gerek geleneksel tarımın gerekse organik tarımın yapıldığı alanlarda, yabancı otlar kontrol altın alınmadığı takdirde, çeşitli düzeylerde ürün kayıpları oluşmaktadır[2]. Son yıllarda damla sulamanın da tarımsal üretimde yaygınlaşması nedeniyle, özellikle bahçelerde/bağlarda sıra üzeri ot mücadelesi, mekanik yöntemlerle yapılamamakta, ayrıca bu alanlarda herbisit kullanımı ağaçlara zarar vermektedir. Ancak, söz konusu tarımsal üretim alanlarında son derece farklı çeşit ve özelliklerde yabancı otlanmalar oluşmaktadır. Özellikle sulu tarım yapılan alanlarda, yabancı otların gelişimi hızlı olmakta ve bu alanlarda sürekli herbisit kullanım gereksinimi bazı yabancı ot çeşitlerinde herbisitlere karşı direnç gelişmiştir. Örneğin, Yabani yulaf (Avena sterilis L.) ve Tilki kuyruğu (Alopecurus myosuroides Huds.) tüm Türkiye' de olduğu gibi Çukurova buğday ekim alanlarında da en önemli dar yapraklı yabancı ot türlerinin başlarında yer almaktadır. Buğday alanlarındaki dar yapraklı yabancı otlara karşı bir ACCase (Acetyl-Coenzyme A Carboxylase) enzim engelleyicisi olan Diclofob-methyl ülkemizde 1984' te ruhsatlandırılmış ve bunu daha sonraki yıllarda aynı kimyasal guruba ait Fenoxaprop-p-ethyl, Tralkoxydim, Clodinafop propargyl, Pinoxaden etken maddeli herbisitler izlemiş̧tir [3]. Ruhsatlandığ yıllardan beri Çukurova' da neredeyse kesintisiz bir şekilde her yıl kullanılan bu ACCase grubu herbisitlere karşı 2000 yıllarına doğru etkisizlik şikayetleri başlamış ve daha sonra ise bu durumun ne yazık ki dayanıklılık problemi olduğu bilimsel çalışmalarla ortaya konulmuştur [4-6]. Yabani yulaf ve Tilki kuyruğu'na ek olarak, buğdayın en önemli geniş yapraklı yabancı otlarından Yabani hardalda da bir başka grup herbisite (Sinapis arvensis L.) dayanıklılı̆̆ın başlamış olduğu düşünüldüğünde [5]. Çukurova'nın buğday üretiminin yabancı otlar yönünden ciddi tehlike altında olduğu çok açıktır. Benzer düzeylerde direnç geliştiren otlara bahçe ve bağ alanlarında da rastlanmaktadir.

Termal yabancı ot kontrolünde kimyasal direnç benzeri sorunlar olmadığından, bitki dokularında yeterli sıcaklığa ulaşıldığında tüm yabancı otların kontrolü sağlanabilir. Bu çalışmada 5 farklı termal yabancı ot kontrol uygulamasının teknik özelliklerine yer verilmiştir. 
Bayat A., Bolat A., İtmeç M.

\section{Materyal ve Metot}

\subsection{Korumalı Alev Uygulaması İle Yabancı Ot Kontrolü}

Alevle yapılan uygulamalar açıkta ve korumalı alev şeklinde yapılmaktadır. Ancak açıkta yapılan alev uygulamalarında, önemli derecede 1sı kayıpları oluşmakta ve bu uygulamalar kültür bitkileri sıra arasındaki yabancı otlarla mücadele sırasında kültür bitkilerine zarar vermektedir. Bu zararı kısmen önlemek için, yuvarlak (sivri) uçlu alev başlıkları kullanılmaktadır. Bu tip alev başlıklarının alev genişliği düşük, dolayısıyla iş genişliği küçük olmakta ve çok sayıda alev başlığının kullanılması gerekmektedir. $\mathrm{Bu}$ durumda kullanılan yakıt tüketimi artmaktadır. Alevle yaratılan 1sı kayıplarını ve alevin kültür bitkisine olan zararlarını önlemek için alev, korumalı bir ortamda üretilecek ve her bir alev başlığının iş genişliğini yükseltmek için yassı uçlu (jet tipi) alev başlıkları kullanılmaktadır.

Korumalı alev uygulamasında sadece alev başlıkları ile yapılan uygulama, standart alev uygulaması olarak adlandırılmaktadır. Bu uygulama ile bitkinin çevresinden aldığı toplam 1sı enerjisi miktarı (Qs) aşağıdaki eşitlikle açıklanabilir.

$$
\sum \mathrm{Q}_{\mathrm{s}}=\mathrm{Q}_{\mathrm{d}}+\mathrm{Q}_{\mathrm{a}}
$$

Burada ;

Qd = Bitkiyi çevreleyen doğal ortamdan alınan ısı miktarı $(\mathrm{kJ})$,

$\mathrm{Qa}=$ Alev uygulamasıyla aldığı ısı enerjisi miktarı (kJ).

\subsection{Sicak Su Uygulamasi ile Yabancı Ot Kontrolü}

Sıcak su uygulaması bilinen en eski termal yöntemlerden biri olup, günümüzde yaygın olarak kullanılmama nedeni genellikle $15-18{ }^{\circ} \mathrm{C}$ deki suyu 1 sıtmak için gerekli yüksek enerji maliyetleri ve ısıtmada kullanılan sistemlerin verimsizliğidir[7]. Ancak ülkemizde özellikle yabancı otlanmanın olduğu dönemlerde yeterli düzeyde güneşlenmenin olması, güneş enerjisi sistemleriyle suyu yeterli sıcaklığa kadar ısıtmayı mümkün kılmaktadır. Güneş kolektörlerindeki $129.1{ }^{\circ} \mathrm{C}$ ’ ye ulaşılabildiği bilinmektedir (Demir Döküm;Solar Roll Bond Kolektör Kataloğundan). Bu sıcaklıktaki suyun, 1sı izolasyonlu bir tanka alınarak düşük basınçta uygulanması yeterli düzeyde yabancı ot kontrolü sağlayabilir. Çünkü, belirtilen sıcaklıktaki suyun otlara iletilmesi, \%30-40 oranında 1sı kayıpları oluşsa bile, bitki hücrelerine zarar verebilecek sıcaklık düzeylerindedir.

Bu uygulama ile bitkinin çevresinden aldığı toplam 1sı enerjisi miktarı (Qs) aşağıdaki eşitlik 2 ile açıklanabilir:

$$
\sum Q_{s}=Q_{d}+Q_{g s}
$$

Burada;

Qd = Bitkiyi çevreleyen doğal ortamdan alınan 1sı miktarı $(\mathrm{kJ})$

Qgs = Güneş enerjisiyle 1sıtılmış su uygulamasıyla aldığı 1sı enerjisi miktarı (kJ)

\subsection{Sıcak Su Püskürtmeli ve Alev Uygulaması ile Yabancı Ot Kontrolü}

Alevle yapılabilen bir başka uygulamada ise, alevle oluşacak yangın risklerini önlemek ve yabancı ot yüzeylerinde daha yüksek 1sı birikimleri sağlamak için, alev ünitesinin ön bölümüne 
yerleştirilecek bir sıcak su püskürtme sistemi ile alevin yabancı ot kontrol etkinliği arttırılmaya çalışılacaktır. Böylece, alevle kontrolü zor veya daha fazla alev-gaz enerjisine ihtiyaç duyan yabancı otlar da kolaylıkla kontrol altına alınabilecektir.

Su püskürtmeli alev uygulaması olarak adlandırılan bu yöntem ile bitkinin çevresinden aldığı toplam 1sı enerjisi miktarı (Qs) Eşitlik 3 ile açıklanabilir:

$$
\sum \mathrm{Q}_{\mathrm{s}}=\mathrm{Q}_{\mathrm{d}}+\mathrm{Q}_{\mathrm{sp}}+\mathrm{Q}_{\mathrm{a}}
$$

Burada;

$\mathrm{Qd}=$ Bitkiyi çevreleyen doğal ortamdan alınan 1sı miktarı (kJ),

$\mathrm{Qsp}=$ Su püskürtme uygulamasıyla aldığı 1sı enerjisi miktarı (kJ),

$\mathrm{Qa}=$ Alev uygulamasıyla aldığı 1sı enerjisi miktarı (kJ),

\subsection{Buharla Yabancı Ot Kontrolü Uygulaması}

Herhangi bir petrol kaynaklı, enerji ya da fosil yakıtla su isitmanın yüksek maliyetlerini azaltmak, doğrudan alevle oluşacak sakıncaların giderilmesi için başvurulan termal yöntemlerden birisidir. Ayrıca alev uygulamada oluşan ısı iletim kayıplarını önlemenin bir yolu ise, ssının buharla hedef üzerine iletilmesidir. $1 \mathrm{~kg}$ buhar, çevresine $2250 \mathrm{~kJ}$ termal enerji yaymakta ve bu enerji $1 \mathrm{~kg}$ gazın (Propan) yaydığı enerjiden 3,7-11 kat daha fazladır. Bu durum Buharlı ortamda, bitki dokularındaki sıcaklık yükselmesini engelleyen terlemenin de oluşmadığını belirtmişlerdir[8]. Böylece buharlı ortam, gazla alevleme ortamına göre, $2000 \mathrm{kez}$ daha büyük etkinlikle çevreyi 1sıtmaktadır. Buharın bir diğer avantajı ise, soğuk bitkiye ve toprak yüzeyine akma eğilimlidir (sıcak ortamdan soğuk ortama akış). Buhar üretiminde de çeşme suyu sıcaklığındaki suyun $130{ }^{\circ} \mathrm{C}$ gibi kızgın buhar sıcaklığına çıkarılması için de bir enerjiye ihtiyaç duyulmaktadır.

Bu uygulama ile bitkinin çevresinden aldığı toplam 1sı enerjisi miktarı (Qs) aşağıdaki eşitlik 4 ile açıklanabilir;

$\sum \mathrm{Q}_{\mathrm{s}}=\mathrm{Q}_{\mathrm{d}}+\mathrm{Q}_{\mathrm{b}}$

Burada:

$\mathrm{Qd}=$ Bitkiyi çevreleyen doğal ortamdan alınan 1 sı miktarı $(\mathrm{kJ})$,

$\mathrm{Qb}=$ Kızgın buhar uygulamasıyla aldığı 1sı enerjisi miktarı (kJ)

\subsection{Infrared Yöntemi ile Yabancı Ot Kontrolü}

İnfrared yöntemiyle yapılan uygulamalarda temel yaklaşım, ya alevle bir metal yüzeyin ya da seramik bir yüzeyin yüksek sıcaklıklarda 1sıtılarak kızıl ötesi 1şınım yaymasını sağlamaktır. Alevle yapılan uygulamalarda hedef yüzeylere ısı taşınımı hava ile sağlanmakta ve bu esnada önemli oranda 1S1 taşınım kayıpları oluşmaktadır. Dolayısıyla havanın iyi bir taşıyıcı olmaması nedeniyle, oluşan ıSı kayıplarını gidermek için infrared yönteminden yararlanılmaktadır. Özellikle bu yöntemde alevin olmaması yangın riskini de azaltmaktadır. Ayrıca bu yöntemde, ışınımla ısının taşınması, yöntemin verimliliğini artırmaktadır. Yöntemin en olumsuz yanı, infrared ışın yayan yüzeyin mümkün olduğunca 
yer yüzeyine (bitki yüzeyine ) yakın olma gerekliliğidir. Bu yöntemin, büyüyen yabancı ot kontrolünde de başarılı olması, yüksek 1sı sağlaması ve kuru otlardaki yangın riskini elemine etmek için, bu araştırmada standart infrared uygulamaya ilave olarak, infrared uygulama ile bir arada yabancı ot yüzeylerine sıcak su püskürtülecektir. Böylece hem yangın riski kalkacak hem de suyun yüksek ısıl kapasitesi nedeniyle daha uzun süre yabancı ot yüzeylerinde 1sı birikimi sağlanabilmektedir.

Standart infrared uygulaması ile bitkinin çevresinden aldığı toplam 1sı enerjisi miktarı (Qs) Eşitlik 5 ile açıklanabilir.

$$
\sum \mathrm{Q}_{\mathrm{s}}=\mathrm{Q}_{\mathrm{d}}+\mathrm{Q}_{\mathrm{kI}}
$$

Standart infrared ile birlikte sıcak su püskürtmeli yöntemde bitkinin çevresinden aldığı enerji miktarı, Eşitlik 6 ile açıklanabilir.

$$
\sum Q_{s}=Q_{d}+Q_{s p}+Q_{k 1}
$$

Burada;

Qd = Bitkiyi çevreleyen doğal ortamdan alınan 1sı miktarı (kJ),

$\mathrm{QkI}=$ Su püskürtme uygulamasıyla aldığ 1sı enerjisi miktarı (kJ),

Qsp = Su püskürtme uygulamasıyla aldığı 1sı enerjisi miktarı $(\mathrm{kJ})$ dir.

\section{Tartışma ve Sonuç}

Kimyasal ilaç kullanmadan çevre dostu teknikler olan Termal yöntemlerin yabancı ot kontrolünde kullanılması ile çevre ve insan sağlığına ciddi katkı sağlanmış olunacaktır. Dünyada ve ülkemizde de son yıllarda giderek artan organik ürün üretim alanlarına rağmen, bu alanlarda yabancı ot mücadelesinde kullanılabilecek başarılı yöntemler bulunmamaktadır. Yoğun iş gücünün bu alanlarda kullanımı, üretim maliyetlerini daha da artırmaktadır. Bu alanlarda ciddi sorun olan yabancı otların termal yöntemlerle kontrol altına alınabilmesi, üretim masraflarını düşüreceği gibi pazara daha sağlıklı ürün sunulması olanağı sağlayacaktır. Keza bu yöntemlerin alışılagelmiş tarımsal üretim yapılan alanlarda da kullanımı mümkün olacaktır. Ayrıca sırta yapılan dikimlerde, sırtları toprak işleme vb. aletlerle bozmadan sırt yüzeylerindeki yabancı otların kontrolü sağlanabilecek, mekanik araçlarla damla sulama sistemlerine verilen zarar önlenerek gerektiğinde lokal ot mücadelesi sağlanabilecektir. Ayrıca ülkemizde çoğu kez yeterli düzeyde güneş 1şınımı olduğundan birçok termal yöntemde güneş enerjisi ile 1sıtılmış su kullanılma potansiyeli bulunması, ülkemizde termal yöntemlerin işletme maliyetlerini de düşecektir. Dolayısıyla üreticiler tarafindan kabul edilebilir maliyetlerle yöntemlerin işletilmesi sağlanabilecektir.

Termal yöntemlerin tarım alanlarında hastalık, zararlı ve yabancı ot kontrolü konusunda ülkemizde yeterli düzeyde çalışma yapılmamış olup, bu konularda yerli düzeyde bilimsel veri bulunmamaktadır. Örneğin hangi termal yöntemlerle hangi tür otların, bitkinin hangi fenolojik dönemde kontrol altına alınabileceği bilinmemektedir.

Ayrıca termal yöntemlerin şehirsel yaşam mekânlarında da kullanımı konusunda önerilerde bulunulabilecektir. Ülkemizde kara yoları ve demir yolları kenarındaki yabancı otlarla mücadelede ya mekanik yöntemler (biçerek) ya da kimyasal herbisitler kullanılmaktadır. Mekanik araçlar özellikle kara 
yolları kenarındaki işaretlere zarar vermekte, bu durum çeşitli trafik kazalarına neden olmaktadır. Zaman zamanda bu alanlarda kurumuş otlar yakılmakta, yükselen duman kaza ve çevre kirliliğine neden olmaktadır. Bu alanlarda termal yöntemlerin kullanılması ile bu sorunların azaltılması mümkündür. Belirtilen bu nedenler ile termal yöntemlere ait teknolojilerin geliştirilmesi ve yaygınlaştırılması bakımından Ar-Ge çalışmalarını daha da arttırılmalıdır.

\section{Kaynaklar}

[1] Tepe, I., "Türkiye'de Tarım ve Tarım Dışı Alanlarda Sorun Olan Yabancı Otlar ve Mücadeleleri” Yüzüncü Yll Üniversitesi Yayınları No: 32, Ziraat Fak. Yayınları No:18, 5-86s, 1998.

[2] Anonymous, "Ruhsatlı Tarım İlaçları, Registered Agrochemicals in Turkey" Hasad Yayıncılı, Kadıköy, İstanbul, 315 s, 2007.

[3] Aksoy, A, Menne, H, Şimşek, M, Büschbell, T., "Yabani Yulaf (Avena sterilis L.)'ın ve Tilki Kuyruğu (Alopecurus myosuroides Huds.)'nun Farklı Herbisitlere Karşı Dayanıklılığı Üzerine Çalışmalar” I. Ulusal Bitki Koruma Kongresi, Samsun, 2004.

[4] Aksoy, A., Kural, İ., Şimşek, V.M., Ünlü, Ş., Sizer, V., "Buğday Ekim Alanlarında Kullanılan Herbisitlere Karşı Dayanıklılık Problemi” Tarım Illaçları, Kongre ve Sergisi, Bildiriler Kitabı, 25-26 Ekim, Ankara. 235-244 s, 2007

[5] Uludağ, S., Nemli, Y., Tal, A., Rubin, B., 2003. ACCase-resistance in wild oat (Avena sterilis) in Turkey. 7th EWRS Mediterranean Symposium, Adana, Turkey

[6] Hansson, D. "Vegetationsreglering med hetvatten på banvallar - försöksverksamhet 1996-1998” Swedish University of Agricultural Sciences, Dept Agricultural Engineering, unpublished report, Alnarp, Sweden. 1999.

[7] Kerpauskas, P., Sirvydas, A.P.,Lazauskas, P., Vasinauskiene, R., Tamosiunas, A. "Possibilities of weed control by water steam”. Agronomy Research, 4 (special issue), 221-225, 2006. 